\title{
Organ Donation, Discrimination After Death, Anti-Vaccination Sentiments, and Tuberculosis Management
}

Bioethical Inquiry. June 2012, Volume 9, Issue 2, pp 125-133

DOI 10.1007/s11673-012-9370-2

Received: 5 March 2012Accepted: 7 March 2012Published online: 18 April 2012

John Coggon (1), Bill Madden (2) , Tina Cockburn(3) , Cameron Stewart(4), Jerome Amir Singh(5, 6, 7), Anant Bhan(8), Ross E. Upshur(9) and Bernadette Richards(10).

(1)Research Fellow, Institute for Science, Ethics, and Innovation, University of Manchester, Manchester, UK

(2)National Practice Group Leader, Medical Law, Slater \& Gordon; Adjunct Fellow, School of Law, University of Western Sydney, Sydney, Australia

(3)School of Law, Queensland University of Technology, Brisbane, Australia

(4)Centre for Health Governance Law and Ethics, Sydney Law School, The University of Sydney, Sydney, Australia

(5)Centre for the AIDS Programme of Research in South Africa (CAPRISA), University of KwaZulu-Natal, Durban, South Africa

(6)Sandra Rotman Centre for Global Health, University Health Network, Toronto, Canada

(7)Dalla Lana School of Public Health and Joint Centre for Bioethics, University of Toronto, Toronto, Canada

(8)McLaughlin-Rotman Centre for Global Health, University Health Network and University of Toronto, Toronto, Ontario, Canada

(9)Sunnybrook Health Sciences Centre, 2075 Bayview Ave, E3-49, Toronto, ON M4N, 3M5, Canada

(10)Adelaide Law School, University of Adelaide, North Tce Adelaide, South Australia, 5005, Australia

John Coggon

Email: John.Coggon@manchester.ac.uk

Bill Madden

Email: bill.madden@slatergordon.com.au

Tina Cockburn

Email: t.cockburn@qut.edu.au

Jerome Amir Singh

Email: singhj9@ukzn.ac.za

Anant Bhan

Email: anant.bhan@srcglobal.org

Ross E. Upshur

Email: ross.upshur@sunnybrook.ca

Bernadette Richards (Corresponding author)

Email: bernadette.richards@adelaide.edu.au 


\section{The British Medical Association Reinvigorates Public Debates on U.K. Organ Donation Policy}

The British Medical Association (BMA), Britain's union and professional association for doctors and medical students, is well-positioned both to spark and contribute to important social and political debates. In a recently published and highly publicised report, it has sought to do so in relation to policies concerning organ transplantation (BMA 2012). Inevitably, much of the debate that this report prompted in the media focused on the ethically more controversial questions: For example, its publication has reignited discussions on "elective ventilation." But the report, whilst presenting the BMA's ethical stance on a wide range of practical and policy questions concerning organ donation, is far from a controversial or partisan polemic. Rather, it is written in the spirit of engaged, public discussion, with a view to developing a consensus, improving U.K. health care, and saving many lives. It provides an accessible resource for anyone interested in a wide range of recent developments regarding organ donation policy in the United Kingdom, along with substantial amounts of information of use and relevance to an international audience.

The report can be seen to work from two basic premises. The first is that organ transplantation represents an inadequately achieved social good, which should be optimised within an ethically and democratically constrained system that accommodates and respects a diversity of views on the moral legitimacy and desirability of organ donation. The second is that policy proposals should be based on the best possible empirical evidence of their efficacy. This can entail learning lessons from other jurisdictions, but demands sensitivity to the fact that practices are defined in part by local particularities that must be accounted for. Having introduced the practical and legal backgrounds, the report analyses two distinct means of improving the United Kingdom's approach to organ donation: first, by developing the infrastructure; second, by increasing the number of donors through the introduction of different policies.

On changing the infrastructure, there is a high level of agreement with an earlier report by the Organ Donation Taskforce (2008), which was set up by the U.K. government in 2006. Notably, the BMA is supportive of a transition to a situation where "all doctors who care for dying patients should see the offer of organ donation as part of their role" (BMA 2012, 18). It also supports the proposition that modest steps should be taken to optimise a living patient's chances of donating organs posthumously if that patient is very close to death and has a wish to become a posthumous donor, even where such steps are not indicated by the patient's narrowly understood medical interests. Another notable point is the BMA's continued rejection of the general acceptability of conditions being attached to the question of who will receive a person's posthumously donated organs.

The BMA report praises the developments following the taskforce's report, noting that its recommendations have largely been implemented. However, it argues that it is important to sustain the momentum that has grown and suggests some areas that require further attention. In particular, the infrastructural reforms need to continue to drive toward increasing referrals for donation, reducing relatives' refusals of consent to donation, considering extending brain stem death testing to neonates, 
and developing consistent acceptance criteria for organs. As well as emphasising the need to maintain the political will to see developments in infrastructure, the report stresses that

[W] hatever systems are put in place, organ donation must continue to be managed and co-ordinated in a coherent fashion and to be seen as an integral part of the end-of-life care pathway. It is only if these changes are protected that the major advances that have been made can be maintained and we can begin to build on the new infrastructure (BMA 2012, 35).

The report then moves to consider possible policies-both ones that the BMA would and would not support-to increase the number of donors. Donation policy requires consideration of matters concerning both living and deceased donors. In regard to living donors, the emphasis lies on voluntariness and the "gift relationship," leading the BMA to reject arguments for a market in organs. In regard to deceased donors, on whom most attention in the report is focused, the BMA has for some time been a strong public advocate of an "opt-out" system to govern donation policy. More specifically, it supports a "soft" system of "opt-out with safeguards" (BMA 2012, 46), which is described as follows:

Under an opt-out system everyone would be assumed to want to donate organs after their death unless, having received information about the system, they had chosen to opt out of donation during their lifetime. ... [The "soft" version of this] system has built-in safeguards, so that the family is always consulted and asked about any unregistered objection and there is scope not to proceed with donation if this would cause severe distress to the family (BMA 2012, 46).

The BMA gives an outline of the practical issues that would need to be addressed if such a policy change were actually to make a difference. (The taskforce had not been convinced in 2008 that a move to optout would achieve the desired effect.) In particular, there would need to be a large publicity campaign, designed to make people think about their wishes concerning posthumous donation. This would also need to pre-empt any possible backlash against donation (e.g., to stop a suspicious public from optingout in protest or because of unfounded concerns that doctors motivated to increase donation rates will not serve their patients' best interests). Also, a database would have to be established, in which people's preferences would be recorded. The new system would change the approach to relatives, who now would not be asked for consent, but asked if they knew of an unregistered objection. And more broadly, it would change the "philosophy" of donation, making it the norm.

From the perspective of scholars following developments in bioethics, particularly those interested in U.K. bioethics, the report provides an interesting representation of the state of recent and contemporary debates. It suggests that the locus of important bioethical inquiry into organ donation has moved in great part beyond "pure philosophy" or battles over who owns terms such as "consent." Although moral arguments receive substantive attention, the most vexing questions seem to be practical rather than philosophical. The debate appears principally to have shifted to assessing what can be done to improve outcomes (i.e., increase donation rates) within, or through realisable amendments to, existing political and infrastructural constraints. This is not to say that morality is not important, simply that the moral argument is only a part of what needs to be assessed. The BMA is concerned about moral imperatives against, for example, coercion and "mandated choice," and sees the idea of 
donation as a gift and clinical need as fundamental ethical principles and the basis of prioritising allocation. In the context of dominant public and academic debates about "nudge" theory (Thaler and Sunstein 2009; Cabinet Office 2010), it is notable, too, how the BMA sees value in information campaigns. However, the structure of the report is such that the different policy proposals considered to have the potential to increase donation rates are evaluated according to various questions: their (probable) effectiveness; ethical considerations; practical considerations; public opinion; and only then expression of the BMA's own view.

The report concludes by stating:

The BMA hopes that the publication of this report will encourage and facilitate debate-amongst health professionals, policy-makers and the public, with a view to reaching broad agreement about the way forward (BMA 2012, 68).

It is to be hoped that this broad agreement will be reached. The report certainly achieves its other aims.

-John Coggon

\section{Discrimination After Death?}

The question of whether the manner of the performance of an autopsy on the body of an HIV-positive person can amount to discrimination was recently considered by the New South Wales Court of Appeal in Sydney Local Health Network v QY and QZ [2011] NSWCA 412.

The relevant legal protections against discrimination considered by the court are statutory in nature, established in New South Wales by the Anti-Discrimination Act 1977 (NSW)(1) ("the Act"); hence, the determination was necessarily focused on the interpretation of the provisions of that particular statute.

\section{Facts}

Mr. B was HIV-positive at the time of apparent suicide in late 2007 ([81], [83]). The Coroner directed a full postmortem be conducted by the Department of Forensic Medicine, which formed part of the Sydney Local Health Network.

The Department of Forensic Medicine did not reconstruct the body after the autopsy, in line with an internal occupational health and safety policy that did not allow reconstruction in the case of bodies with certain conditions, one of them being HIV-positive status ([83]). The Department of Forensic Medicine released the body to a private undertaker. Whilst not prevented by law from proceeding to reconstruct, the undertaker advised that-due to the state in which the body was receivedreconstruction was not feasible ([84]).

${ }_{1}$ Other statutory protections exist in Australia. See, for example, the Disability Discrimination Act 1992 (Cth) and the AntiDiscrimination Act 1991 (Qld). 


\section{Application}

The primary application that eventually led to the present Court of Appeal decision was made by QY, a long-time friend of the deceased, and QZ, who was his homosexual partner ([82]). They claimed to be "associates" of the deceased within the meaning of the Act and aggrieved, as they were forced to reveal to members of the deceased's family (who were previously unaware of Mr. B's condition) the reason for B's death and why his body had not been reconstructed ([84]).

QY and QZ complained of discrimination by the coronial services managed by the Department of Forensic Medicine on the grounds that they suffered unlawful discrimination due to the condition in which the body of their deceased associate was returned to them after forensic pathology. They claimed they were treated differently, as compared to next of kin whose relatives die free of disability ([85]). This was because the regular practice of the Department of Forensic Medicine was to reconstruct the body after a post mortem and before releasing it ([167]).

Specifically, QY and QZ alleged there was discrimination in the provision of services within the meaning of s 49M: "It is unlawful for a person who provides ... services to discriminate against a person on the ground of disability ... by refusing to provide the person with those ... services" ([6]).

The relevant definition of discrimination on the ground of disability appears in s 49B:

(1) A person (the perpetrator) discriminates against another person (the aggrieved person) on the ground of disability if, on the ground of the aggrieved person's disability or the disability of a relative or associate of the aggrieved person, the perpetrator:

(a) treats the aggrieved person less favourably than in the same circumstances, or in circumstances which are not materially different, the perpetrator treats or would treat a person who does not have that disability or who does not have such a relative or associate who has that disability.

The contravention of s $49 \mathrm{~B}(1)$ was said to have occurred at the time that the Department of Forensic Medicine returned Mr. B's body to QY and QZ in an unreconstructed state. It was argued that, by returning Mr. B's body to them in an unreconstructed state-a decision made on the basis Mr. B's disability (constituted by being HIV-positive) - the Department treated QY and QZ less favourably than it would have treated a person whose associate had no disability ([8]).

The application was initially dismissed, but an Appeal Panel reversed the decision of the Magistrate and remitted the case for trial. Essentially it did so because it considered that a "person" under the Act included a deceased person ([91]).

Sydney Local Health Network successfully sought leave to appeal that decision and a review by the Court of Appeal ([104]). 
Issues

Sydney Local Health Network's substantive response to the case brought by QY and QZ was that the deceased could not be a "person" and, in any event, that QY and QZ could not be "associates" of a deceased person. Those terms required interpretation in the context of the Act.

Other issues were considered, such as the possibility of a statutory protection of a doctor conducting a post mortem under the then Coroners Act 1980 (NSW) ([153]-[166]).

Young JA wrote the lead judgment, finding that the deceased was not a person under the Act ([128]) and that QY and QZ were not his associates ([145]). Macfarlan JA agreed with Young JA as to the interpretation of the term "associate" ([76]), as did Campbell JA ([54]). That finding was sufficient for the appeal to succeed and for the argument of QY and QZ to fail. Costs of the appeal were payable by the respondents ([178]).

\section{Was the Deceased a "Person"?}

Justice Young had little difficulty in holding that the deceased was not, at the relevant time, a person within the meaning of the Act, commenting that: "The whole context of the Act points to a person being a living person who may suffer from the discrimination" ([117]). Justice Macfarlan did not find it necessary to decide that question, noting that for the reasons given by Campbell JA-who was not "persuaded that it is only a living person who can be a 'person' within the meaning of the Act" ([2])-the issue was one of some complexity, which may be resolved in different ways depending upon the context in which it arises ([77]).

\section{Were QY and QZ “Associates” of the Deceased?}

Whilst the Act also permitted an application by a relative, neither QY nor QZ met the s 4 definition that required they be "any person to whom the person is related by blood, marriage, affinity or adoption."

QY and QZ applied under the $s 4$ definition that stipulates "associate of a person means: (a) any person with whom the person associates, whether socially or in business or commerce, or otherwise, and (b) any person who is wholly or mainly dependent on, or a member of the household of, the person." The crucial finding by Young JA was shortly stated:

The definition of "associate" focuses on any person with whom the person associates. As Mr B was not a person at the time of the alleged discrimination and as a deceased person at that time does not have people with whom he associates at that time, it must follow that neither QY nor QZ are associates who can complain of discrimination ([145]).

Campbell JA ([2]) and Macfarlan JA ([75]) agreed with this conclusion.

Despite being raised during oral submissions, there was no full consideration in the judgments as to the ambit of s 49P of the Act ([129]-[140]), which provides that "nothing in this part renders unlawful 
discrimination against a person on the ground of disability if the disability concerned is an infectious disease and the discrimination is reasonably necessary to protect public health."

\section{An Incidental Issue-Immunity}

Obiter comment was made by Young JA as to the possible application of s 52A of the Coroners Act 1980 (NSW): "Nothing done by a medical practitioner or other person in good faith for the purposes of making a post mortem examination, or a special examination or test, pursuant to a direction under this Act subjects the person personally to any action, liability, claim or demand."

Under that section, he said, one would think that the medical practitioners who were involved in the post mortem would be exempt from any civil liability ([157]). There was also a suggestion that there was no liability with a postmortem being conducted under the direction of the Coroner forming a part of the judicial process ([162], referring to s 44B of the Judicial Officers Act 1986 (NSW); thus, the Local Health Network was not vicariously liable ([163]).

-Tina Cockburn and Bill Madden

\section{Anti-Vaccination Sentiments and Health Care Complaints}

Recently, the NSW Supreme Court has upheld claims by the Australian Vaccination Network (AVN) that it should not be forced to placed warnings on its website regarding the information it promotes on vaccination risks (Australian Vaccination Network Inc v Health Care Complaints Commission [2012] NSWSC 110).

The AVN is a northern NSW-based group that claims to provide educational materials on vaccination but is viewed by many as being anti-vaccination in nature. Two complaints were lodged against the AVN with the Health Care Complaints Commission (HCCC) alleging that the AVN had engaged in misleading or deceptive conduct in order to dissuade people from being or having their children vaccinated. After investigating the claims, the HCCC ordered the AVN to publish a disclaimer on its website and, when the AVN refused to do so, the HCCC issued a public warning:

The AVN's failure to include a notice on its website of the nature recommended by the Commission may result in members of the public making improperly informed decisions about whether or not to vaccinate, and therefore poses a risk to public health and safety (HCCC 2010, 19).

Soon after, the AVN lost its charitable status under the Charitable Fund Raising Act 1991.

The AVN then went to court to argue that the HCCC's decisions were beyond power, as the AVN was not a "health service provider." Adamson J found (at [45]) that the HCCC only had the power to regulate health service providers and that required that the "service ... has a concrete (even if indirect) effect on a particular person or persons ... within jurisdiction. Complaints about health services that have a tendency to affect a person or group, but which cannot be shown to have had an effect, would appear to be excluded." After analysing the evidence, Adamson J found (at [59-60]) that the AVN had not affected the health care of a particular person: 
59 Although I find that both complaints concern the health service that the plaintiff provides, the health service has not been shown to "affect the clinical management or care of an individual client". Although it might have that tendency, and although the plaintiff hopes to have that effect, I do not consider this to be sufficient to establish that it has had that effect.

60 I do not consider the evidence to be relied upon by the HCCC to be sufficient that there was such a causal link, or that any link could be established in respect of "an individual client". Had the HCCC apprehended that such would be required to found jurisdiction, it presumably could have readily obtained such evidence from one of the complainants. However, the ease with which it might have done so is not the test. It did not do so. As I have found, the evidence adduced before me is not sufficient to bring the complaints within s 7(1)(b) of the Act.

On that basis, the court found that the HCCC had no power to investigate the claims against the AVN or issue its direction and public warning. The decision is significant in the way that shows a jurisdictional gap in the HCCC's powers to investigate and curb the provision of misleading health information. Perhaps another tack would be for other regulators such as the Australian Competition and Consumer Commission to investigate the AVN for misleading and deceptive conduct, but that entity's powers are based on companies being involved in "trade and commerce."

-Cameron Stewart

\section{TB Management in India: Public Health, Ethics, Social Considerations, and Human Rights}

India accounts for about one-fifth of the global burden of tuberculosis (WHO 2010b). In 2008, there were almost 100,000 cases of multidrug resistant tuberculosis (MDR-TB) (WHO 2010c), which amounts to more than 20 percent of the global incidence (Bhatia 2010). Traditionally, TB diagnosis in India, like similar resource-constrained settings elsewhere, has been hampered by slow turnaround times. However, the new Xpert MTB/RIF test has demonstrated sensitive detection of TB as well as Rifampicinresistance directly from untreated sputum in less than two hours (Boehme et al. 2010). It thus holds the promise of advancing TB surveillance by yielding rapid, reliable, and accurate TB diagnosis. Notwithstanding its shortcomings-high cost, limitations in testing only for Rifampicin-resistance, detection of a relatively small number of mutations, and inability to indicate which patients are sputum smear-positive (Small and Pai 2010) -its introduction in resource-constrained settings promises to change the TB landscape. India's current TB management strategy, however, in which the state sector relies primarily upon smear microscopy for TB diagnosis while the country's private sector heavily uses serological testing to diagnose TB (Specter 2010), presents a growing public health humanitarian disaster and serious opportunity cost and, thus, merits urgent revision. This work considers the ethical implications of the wide misuse of serological TB tests in the Indian health sector. It also briefly reviews some of the social and human rights implications of introducing the Xpert MTB/RIF test in India. 


\section{Rethinking Diagnostic Technologies}

Tackling TB in India will require a shift in thinking about diagnostic strategies. Almost half of TB patients in India may seek care initially in the private health care sector, where serological testing is widespread (Steingart, Pai, and Dowdy 2010; Ghanashyam 2011) and diagnostic, treatment, and reporting practices often do not meet national or international standards for TB (Uplekar et al. 1998; Sehgal et al. 2007). Currently, the market value for serological testing in India's private sector is conservatively estimated at no less than US\$15 million per annum (Steingart, Pai, and Dowdy 2010; Ghanashyam 2011). In comparison, the Indian government's Revised National TB Control Programme's (RNTCP) total budget in 2008 was US\$67 million (Muniyandi et al. 2010). Despite the extensive use of serological testing in India, no international guidelines recommend serological TB tests for clinical use and no serological TB test has been approved by the U.S. Federal Drug Administration. Further, systematic reviews of commercial serological antibody detection tests for the diagnosis of pulmonary tuberculosis have demonstrated the shortcomings of this technology for pulmonary TB diagnosis (Pai, Ramsay, and O'Brien 2008; Steingart et al. 2007a, b), leading one such study to conclude that this technology has "little or no role in the diagnosis of pulmonary tuberculosis" (Steingart et al. 2007b, 1041). This mounting evidence has led the Tuberculosis Coalition for Technical Assistance (TBCTA), whose partners include the World Health Organization (WHO) and the International Union Against TB and Lung Disease, to declare: "serological tests are not of proven value and should not be used in routine practice at this time" (Tuberculosis Coalition for Technical Assistance 2009, 31). The WHO expert group and Strategic and Technical Advisory Group on Tuberculosis (STAG-TB) have concluded that serology testing for TB is unreliable. In July 2011, the WHO issued an unprecedented negative recommendation regarding the use of serological tests for active TB diagnosis (Stop TB Partnership 2011). Based on this, the laboratory committee of the RNTCP issued a letter endorsing the WHO expert group recommendations and advised the central TB division in the health ministry to disseminate the information in India (Deputy Director General, Head Central TB Division, Project Director RNTCP 2011). This is a welcome step for TB control in the country. However, just issuing a letter supporting the recommendations of the WHO expert group is not enough. The Indian government needs to actively ban the use of TB serological tests and ensure compliance in the interests of public health. In addition, the government needs, where feasible, to supplement the use of smear microscopy with newer, more promising technologies such as Xpert MTB/RIF. The Indian government should also encourage operational research that considers various permutations and combinations of new and existing technologies (including smear microscopy but excepting serology) to determine the optimal mix for India.

Patient care should be centred on evidence-based practice. As such, the continuing usage of serological tests for TB diagnosis violates patient rights as the tests are unreliable. Further, as serological testing is comparatively expensive and is usually paid for by patients directly, it imposes an unjustifiable financial burden on patients. The test results might be used to initiate treatment that is clinically not indicated, thus putting patients at risk of unnecessary side-effects of prescribed medications. Alternatively, treatment might not be initiated when indicated, leading to TB patients not being treated in time. This not only adversely affects the patient's health but also potentially creates significant public health 
concerns. Clinical use of such tests is, thus, clearly unethical and needs to be curbed by physicians and medical associations.

\section{Human Rights, Ethics, and Social Challenges Implicit in Rolling Out the Xpert MTB/RIF Test in India}

While the WHO has endorsed rapid diagnostic tests such as liquid culture (BACTEC/MGIT), molecular line probe assays, and rapid strip-based detection and speciation (WHO 2010a), the rollout of the Xpert test-which demonstrates superior performance to the aforementioned technologies-in a resourceconstrained setting such as India raises numerous challenges.

In instances where novel rapid TB diagnostic technologies such as Xpert MTB/RIF reveal that patients are infected with drug-resistant forms of TB (and, accordingly, potentially incurable), authorities may have to consider imposing relevant liberty-restricting measures on these individuals as a last resort if they refuse to comply with infection-control directives. Such measures may affect the infected individual's liberty, livelihood, and dignity (Singh, Upshur, and Padayatchi 2007; WHO 2010c). Liberty-restricting measures may also necessitate authorities initiating relevant social security or assistance mechanisms to support those whose rights are being restricted. These might include social security grants where isolation of the infected individual is warranted and particularly in instances where the infected individual is a primary or sole breadwinner and/or caregiver. Such measures will satisfy the public health ethics principle of reciprocity, which requires the state and society to compensate those who make sacrifices for the greater good. Such social security or assistance services may even be constitutionally mandated in some settings (Singh, Upshur, and Padayatchi 2007; WHO 2010a, b, c, d). While the right to social security is not explicitly recognised in the Indian Constitution, Article 41 of the Indian Constitution states: "The State shall, within the limits of its economic capacity and development, make effective provision for securing the right to work, to education and to public assistance in cases of unemployment, old age, sickness and disablement, and in other cases of undeserved want." (2)

If inadequate TB treatment facilities (especially for the treatment of drug-resistant forms of TB) exist in the public sector, the Indian government may have to consider home- or community-based isolation and care. In such instances, relevant training for caregivers and the provision of universal precautions will have to be made available to health personnel, caregivers, and other individuals at risk of infection. However, the merits of home-based care for drug-resistant forms of TB in India will have to be given careful thought, particularly in the urban context given the generally overcrowded conditions of most urban informal settlements in the country. Aside from the public health implications of housing drugresistant infected individuals in such overcrowded settings, a key ethical issue here is that, if household contacts of MDR-TB patients are found to have latent TB infection, there is really no straightforward treatment option. And in many countries including India, latent TB infection is rarely treated.

2 The Constitution of India is available at http://lawmin.nic.in/ coi/coiason29july08.pdf. 
Because of the stigma associated with TB in some settings (particularly in the case of potentially incurable drug-resistant strains), authorities will have to initiate and/or ramp-up relevant mythdispelling and stigma-mitigating measures - such as awareness campaigns that emphasize that TB is usually curable (acknowledging, though, that cure rates are poor in MDR-TB) and that highlight the human rights of those infected. Such measures will satisfy the ethics principle of solidarity, which emphasizes standing by and aiding those who need assistance.

\section{TB Treatment and Management: A Need for Renewed Research and Funding}

Besides the challenges outlined in above, it also is prudent to remember that there has been a lack of research and development focused on new TB drugs. As a disease of continuing global health importance, there is a need for the development of new regimens that offer more efficient TB control, especially against the backdrop of rising TB resistance rates. The Indian government and medical research bodies must take a leadership in this area.

TB management in India requires a radical overhaul and urgently. This will require moral and political fortitude and will undoubtedly have major resource, human rights, ethics, and social implications. However, maintaining the current status quo is not an option and will have dire public health implications for the country. What's more, it is morally indefensible.

-Jerome Amir Singh, Anant Bhan, and Ross E. Upshur

Acknowledgments.

The views expressed by the authors in the section "TB Management in India: Public Health, Ethics, Social Considerations, and Human Rights" are their own. These authors thank Jocalyn Clark, Peter A. Singer, Shane Green, Peter Small, Madhukar Pai, Anjali Nayyar, Sukriti Chauhan, David Gold, and Renaud Boulanger for their comments on earlier drafts of the manuscript.

Contributions

Jerome Amir Singh and Anant Bhan drafted the manuscript. Ross E. Upshur provided key input thereon.

Funding

The Bill and Melinda Gates Foundation is the primary source of funding for the project related to "TB Management in India." Jerome Singh also receives support from the Centre for the AIDS Program of Research in South Africa, which forms part of the Comprehensive International Program of Research on AIDS funded by the National Institute of Allergy and Infectious Disease at the National Institutes of Health and the U.S. Department of Health and Human Services. Ross E. Upshur also receives support from the University of Toronto's Joint Centre for Bioethics through a Canada Research Chair and from the Sunnybrook Health Sciences Centre in Toronto. The funders had no role in the decision to submit or in the preparation of this paper, other than providing comments on earlier drafts.

Conflict of interest

The authors associated with the section "TB Management in India" work on the ESC2 Program in Global Health, which is funded by the Bill and Melinda Gates Foundation. Earlier versions of the manuscript were circulated to program officers of the funder, who had an opportunity to provide comments. 


\section{References}

Bhatia, V. 2010. Enhancing private sector contribution to TB care in India. Geneva: The Global Fund to Fight AIDS, TB and Malaria.

http://tbpartnershipindia.org/documents/Enhancing\%20private\%20sector\%20contribution\%20to\%20TB \%20care\%20in\%20India.pdf.

Boehme, C.C., P. Nabeta, D. Hillemann, et al. 2010. Rapid molecular detection of tuberculosis and rifampin resistance. The New England Journal of Medicine 363(11): 1005-1015.PubMedCrossRef

British Medical Association [BMA]. 2012. Building on progress: Where next for organ donation policy in the UK? London: British Medical Association.

Cabinet Office Behavioural Insights Team. 2010. Applying behavioural insight to health. London: Cabinet Office.

Deputy Director General, Head Central TB Division, Project Director RNTCP. 2011. No title. http://tbcindia.nic.in/pdfs/Letter Serodiagnosis.pdf. Accessed March 7, 2012.

Ghanashyam B. 2011. Tuberculosis diagnostics: Innovating to make a difference. Expert Review of AntiInfective Therapy 9(4): 381-384. http://www.expert-reviews.com/doi/pdf/10.1586/eri.11.18.

Health Care Complaints Commission [HCCC]. 2010. Public warning about Australian Vaccination Network (AVN). ttp://web.archive.org/web/20110718000811/http://www.hccc.nsw.gov.au/Publications/MediaReleases/PUBLIC-WARNING-/default.aspx.

Muniyandi, M., R. Rajeswari, R. Balasubramanian, A. Thomas, T. Santha, and P.R. Narayanan. 2010. India's Revised National Tuberculosis Control Programme (RNTCP): Budget and performance. Journal of Health Management 12(3): 261-271.CrossRef

Organ Donation Taskforce. 2008. Organs for transplants: A report from the Organ Donation Taskforce. London: Department of Health.

Pai, M., A. Ramsay, and R. O'Brien. 2008. Evidence-based tuberculosis diagnosis. PLoS Medicine 5(7): e156. doi:10.1371/journal.pmed.0050156.PubMedCrossRef

Sehgal, S., P.K. Dewan, L.S. Chauhan, S. Sahu, F. Wares, and R. Granich. 2007. Public-private mix TB activities in Meerut, Uttar Pradesh, North India: Delivering dots via collaboration with private providers and non-governmental organizations. The Indian Journal of Tuberculosis 54(2): 79-83.PubMed

Singh, J.A., R. Upshur, and N. Padayatchi. 2007. XDR-TB in South Africa: No time for denial or complacency. PLoS Medicine 4(1): e50. doi:10.1371/journal.pmed.0040050.PubMedCrossRef

Small, P.M., and M. Pai. 2010. Tuberculosis diagnosis-time for a game change. The New England Journal of Medicine 363(11): 1070-1071.PubMedCrossRef 
Specter, M. 2010. A deadly misdiagnosis: Is it possible to save the millions of people who die from TB? The New Yorker, November 15.

http://www.newyorker.com/reporting/2010/11/15/101115fa_fact_specter. Accessed September 15, 2011.

Steingart, K.R., M. Henry, S. Laal, et al. 2007a. A systematic review of commercial serological antibody detection tests for the diagnosis of extrapulmonary tuberculosis. Thorax 62(10): 911-918.

Steingart, K.R., M. Henry, S. Laal, et al. 2007b. Commercial serological antibody detection tests for the diagnosis of pulmonary tuberculosis: A systematic review. PLoS Medicine 4(6): e202.

doi:10.1371/journal.pmed.0040202.CrossRef

Steingart, K.R., M. Pai, and D. Dowdy. 2010. Serological tests for tuberculosis: The evidence is reviewed. Paper presented November 11 in Berlin, Germany.

http://www.stoptb.org/wg/new diagnostics/assets/documents/3.1 KarenSteingart SerologicalTests.pd f.

Stop TB Partnership. 2011. WHO warns against the use of inaccurate blood tests for active tuberculosis. http://www.stoptb.org/news/stories/2011/ns11_050.asp. Accessed September 15, 2011.

Thaler, R., and C. Sunstein. 2009. Nudge: Improving decisions about health, wealth, and happiness. London: Penguin.

Tuberculosis Coalition for Technical Assistance. 2009. International standards for tuberculosis care: Diagnosis, treatment, public health, 2nd edition. The Hague: Tuberculosis Coalition for Technical Assistance. http://www.tbcta.org/Uploaded files/Zelf/ISTCReport2ndEdition1258118339.pdf.

Uplekar, M., S. Juvekar, S. Morankar, S. Rangan, and P. Nunn. 1998. Tuberculosis patients and practitioners in private clinics in India. The International Journal of Tuberculosis and Lung Disease 2(4): 324-329.PubMed

World Health Organization [WHO]. 2010a. Framework for implementing new tuberculosis diagnostics. Geneva: World Health Organization.

http://www.who.int/tb/laboratory/whopolicyframework july10 revnov10.pdf.

World Health Organization [WHO]. 2010b. Global tuberculosis control 2010. Geneva: World Health Organization. http://whqlibdoc.who.int/publications/2010/9789241564069 eng.pdf.

World Health Organization [WHO]. 2010c. Guidance on ethics of tuberculosis prevention, care and control. Geneva: World Health Organization. http://whqlibdoc.who.int/publications/2010/9789241500531 eng.pdf.

World Health Organization [WHO]. 2010d. Multidrug and extensively drug-resistant TB (M/XDR-TB): 2010 global report on surveillance and response. Geneva: World Health Organization. http://whqlibdoc.who.int/publications/2010/9789241599191 eng.pdf. 